\title{
Designing a Primary Personal Information Market as an Industry Platform: a Service Innovation Approach
}

\author{
Ross Farrelly \\ University of Technology, Sydney \\ ross.w.farrelly@student.uts.edu.au
}

\author{
Eng Chew \\ University of Technology, Sydney \\ eng.chew@uts.edu.au
}

\begin{abstract}
It is well recognised that personal data have intrinsic value to B2C companies. However, there are no widely adopted means by which individuals can benefit financially from the personal data they generate. Furthermore, there is a substantial lack of empirical research on markets for online personal data. Nevertheless, prior work has shown that a Primary Personal Information Market (PPIM) is a viable solution to the problem of monetising personal data. This paper explores how a PPIM could be conceptualised and designed as an Industry Platform. Using an integrated Service Innovation Method (iSIM) we incorporate into our design a multi-sided personal information business model to facilitate commercialisation. An initial prototype is developed and its utility from a data product consumer's perspective is evaluated using semi-structured interviews with industry practitioners. We find that a PPIM conceptualised as an industry platform has significant commercial appeal and that it resolves a number of objections raised in response to previous designs.
\end{abstract}

\section{Introduction}

As mobile and wearable technology continues to evolve it is becoming easier than ever to capture an ever-increasing volume of personal information[1], information which is not only voluminous but also increasingly detailed and therefore of great value to organisations [2]. However, currently there are no readily available means by which an individual can receive financial compensation for granting access to his or her personal information. As we have argued elsewhere [reference removed] one solution to this is the Primary Personal Information Market (PPIM). A PPIM is a market in which the primary producer of personal information sells access to that information in some form to a consumer who wishes to benefit from it. This stands in contrast to the secondary personal information market [3] in which a secondary party gains financial benefit by selling other individuals' personal information.

This paper is written in the context of a broader research project to design and develop a PPIM[4]. Previous research and evaluation of an individual facing prototype shows that a PPIM is broadly speaking, viable [5] and should be permissions based [6] and that there is likely to be significant appetite from individuals to participate on such a market.

A second iteration in the design science process [7-9] is required to redesign for scalability and to explore the potential for commercialising a PPIM through the provisioning of a variety of possible personal data products (PDPs). Consequently, we employ the integrated Service Innovation Method (iSIM) as a framework by which to design PPIM as an industry platform for innovative personal data service delivery [10].

iSIM is "an integrated cross-disciplinary, holistic method to design and commercialize service innovation" [11:1]. It is a method to simultaneously design an innovative service offering and an associated business model with the aim of engendering sustained value co-creation between customer and firm.

The research question we seek to address is: How can a PPIM be conceptualised and prototyped as an industry platform using iSIM?

This paper is relevant because it simultaneously deepens and improves the design of a PPIM and also demonstrates a novel application of the iSIM. It will be of relevance to researchers in a plurality of disciplines including design science, service innovation and platform development because it applies a novel design approach in an industry platform setting and develops a novel conception of a large scale market for personal information.

This paper makes a contribution to the literature by improving and refining the design of a PPIM in the light of the evaluation from previous research. It further reconceptualizes a PPIM as an industry platform and explains how value can be co-created between PPIM stakeholders with a view towards PPIM commercialization. It also demonstrates the efficacy of iSIM as an innovation method for industry platform design.

This paper is organised as follows. Section 2 outlines the background to the research including both platform theory and markets in personal information. Section 3 describes the method utilised for the research while section 4 presents the proposed design solution, organized in subsectioned according to the iSIM. Section 5 describes the prototype which instantiates the design. Section 6 presents the results of the evaluation of the prototype. Section 7 concludes the paper while section 8 outlines avenues of further research. 


\section{Background}

The references in this section were sourced using a process similar to Kitchenham's systematic literature review methodology [12] by searching Business Source Complete, ACM Digital Library, IEEE Explore, ProQuest and Scopus for the phrases "platform theory", "industry platform", "product platform", "personal information markets" and "online marketplace design".

The concept of the platform originated in manufacturing where product platforms were developed as a core base to which features could be added to meet customer needs [13]. These platforms evolved into systems along with their associated interfaces, which were used as a standardized substratum upon which complex and customized products could be efficiently produced $[14,15]$. The concept of the industry platform (often associated with the concept of the "keystone firm" [16]) further evolved to encompass software-based products and services [17]. While Thomas et al [18] identified four main types of platform, a binary distinction can be drawn between internal (company or product) platforms and external (or industry) platforms.

An industry platform is defined to be "products, services, or technologies that ...provide the foundation upon which outside firms ... can develop their own complementary products, technologies, or services" [19:418]. An m-sided $(m \geq 2)$ platform facilitates a market by connecting $m$ groups of users which provide each other with network effects. [20]

There are three key aspects to an industry platform: a relatively stable core component, versatile, complementary peripheral components and a stable interface component which links the two [21].

Industry Platforms are open [19], in the sense that third party companies can interact with an industry platform in order to develop and create their own products. Industry platforms are also scalable [22], able to accommodate a large volume of both actors who wish to interact with them. Two other related characteristics of industry platforms are their ability to adapt and evolve [19] i.e. they are able to adjust and accommodate unanticipated changes in the external business environment. Industry platforms are also modular and non-deterministic or emergently generative [17-19] in the sense that they do not determine the end use of products which are built upon them.

Recent developments in platform theory focus on linking two previously separate conceptions of the nature of a platform: the market perspective and the engineering perspective. From the market perspective Gawer [23:421] argues that Industry Platforms must "perform a function that is essential to a broader technological system" and "solve a business problem for many firms and users in the industry". Gawer [19] also emphasises that industry platforms must act as multi-sided markets, facilitating the co-creation of value from multiple contributors. Such multi-sided markets provide "goods or services to several distinct groups of customers, all of whom need each other in some way and rely on the platform to mediate their transactions" [19:422].

Research into markets in personal information is multi-dimensional and cross-disciplinary and touches on numerous areas of related research such as: data ownership [24, 25], privacy [26, 27], personal informatics [28, 29], the collection and modelling of personal information $[30,31]$ and data security $[32,33]$. However, as noted by e-market scholars, "there is a substantial lack of empirical research on ... markets for online personal data" [34] and most market design research is qualitative [35].

Spiekermann and Novotny [36] explored the tension between sharing personal information with companies while maintaining personal privacy. By focusing on the type of relationship which exists between the individual and the company, they developed a four-space model of personal information management. It has also been proposed that individuals receive compensation for allowing their data to be included in a sample from which the buyer sought to infer a statistic of interest about a population [37] and for the allowing access to sensor data generated by the Internet of Things [24].

Other researchers $[38,39]$ have alluded to the need for a marketplace for personal information without explicitly calling for a PPIM. They have identified the need for individuals to retain ownership of their personal information, to have more control over their privacy [40] and have identified a growing number of start-ups which focus on the value of data usage rather than the value of data itself [34].

Farrell and Chew [4] propose a permissions based PPIM on which individuals receive compensation for granting access to their personal data. However, these markets only involve two actors, individuals supplying the personal information (the raw materials) and companies purchasing the PDPs.

In summary we see that, while the issue of personal information and its inherent value has been approached by numerous scholars from many perspectives, there is little (if any) research which examines a personal information market, both from an economic and engineering perspective, as an industry platform. This represents a significant gap in the literature as a scalable multi-sided PPIM which incorporates input from multiple contributors has many of the characteristics of an industry platform and would therefore benefit from being conceptualised as such. 


\section{Method}

Following the iSIM we explore the initial design of a PPIM in terms of the service business strategy, customer type and customer value proposition, the service concept, the service system, customer experience, service architecture and monetisation. In practice the application of iSIM will be non-linear and agile - in the sense that entrepreneurs implementing a PPIM may follow different (iterative) paths through the design process. However, we describe the design process sequentially for the sake of logical design information flow. We outline how a PPIM would incorporate these perspectives in a multi-sided market (see section 4) and then instantiate the design in a prototype (described in section 5).

Using semi-structured interviews, in accordance with design science, we evaluate the PPIM industry platform qualitatively [41]. These interviews were conducted with reflective practitioners [42] some of whom worked in data related roles. They were selected on the basis of their subject matter expertise [57], both data related and business related. This is consistent with other studies; see for example [43-45].

We interviewed representatives (who are considered to be potential target PPIM product/service consumers) from eight businesses, one from each of Education, Cultural and Recreational Services; Accommodation, Cafes and Restaurants; Government Administration and Defence; and Communication Services and two from each of Finance and Insurance and Personal and Other Services [46]. There was one micro, two small, three medium and two large businesses.

The aim of the evaluation was to gather opinions from interviewees on the following key implementation factors: the feasibility of building a PPIM as an industry platform, the viability of such a PPIM if it were to be built, and the appetite that companies might exhibit to participate in such a PPIM, additional PDPs which could also be created on the PPIM so described and any issues which may prevent or impede the workability of the PPIM.

The selection of interviewees was guided by theoretical sampling [47] in which we sampled experts who could evaluate the constructs and structure of the proposed designs based on their domain expertise and years of experience. Interviewees had an average of 22.25 years' experience (as indicated by their LinkedIn profiles).

An interview topic guide [48] was used for interview consistency. After a brief explanation of the purpose of the research and the proposed PPIM industry platform the interviewees were presented with a demonstration of the prototype. They were asked their opinions on the feasibility of the PPIM industry platform and if they identified any major flaws or issues with the proposed solution. They were asked whether or not such a market would be viable, and based on their experience whether there was appetite for companies to purchase PDPs on a PPIM and about the willingness of individuals to share personal information on such a market. They were asked to conceive of any novel personal data product ideas of value to their business which could be provisioned on the proposed PPIM. They were asked which departments (if any) within their businesses would use the proposed PPIM on a daily basis. The average duration of the interviews was 44.6 minutes.

\section{Design Solution}

\subsection{Service business strategy design}

The business strategy envisioned for the proposed PPIM is an instantaneous "build-to-order" logic [49] associated with a virtual marketplace. The raw materials (personal data) are ingested via data feed connections. The output from models which have extracted inferred information from the raw data are also present in the centralized data store. The data product consumer co-creates his or her customized PDP with PPIM by selecting an appropriate PPIM-provisioned template and populating it with the requisite components to customize the PDP. After previewing the PDP the consumer creates the PDP which is instantaneously built-to-order at the completion of the customization process. When the PDP is executed, the platform facilitates the revenue distribution from the purchaser to the contributors to the PDP.

While the prototype presented in this paper is a 4-sided market the PPIM industry platform's strategic intent is towards becoming an m-sided market $(m>4)$. Additional stakeholders who could participate on a PPIM include (but are not limited to) PDP template developers, plug in developers to interface PDS API with company ERP or CRM systems, experimental developers to facilitate experiments and $\mathrm{A} / \mathrm{B}$ testing on PDP usage, personal data brokers to manage access to personal data on behalf of individuals, pricing model developers to test alternative pricing models such as auctions, reverse auctions and pricing for exclusive use.

\subsection{Customer type and customer value proposition design}

Designing the customer type and customer value proposition (CVP) is an iterative process [11]. Following the first iteration of the design process [6] we now propose four distinct types of participants which could participate on a PPIM to co-create value from personal data: data contributors, model developers, data feed developers and personal data product consumers (see Figure 1 below). 
Data contributors have the role of granting permission for their data to be collected on their behalf, stored in the centralised data repository and for granting permission for their data to be included in the PDPs to which they give their consent. The value proposition to data contributors is the full control of their personal data

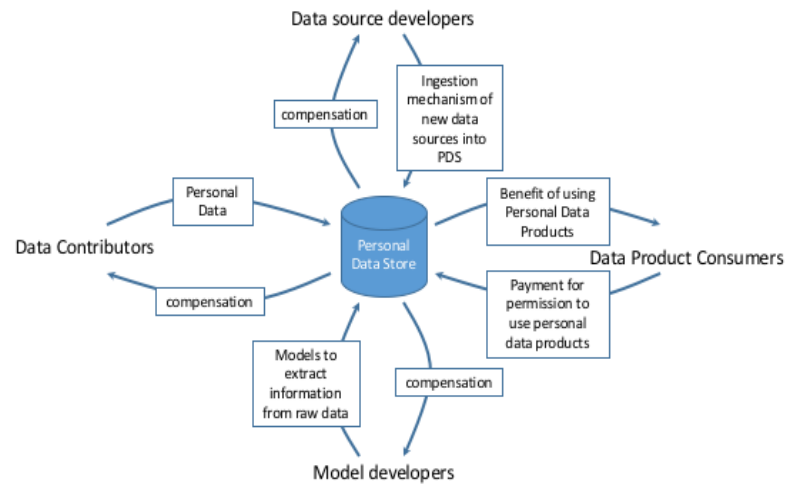

Figure 1: Four participant types and value propositions on a PPIM

and the financial compensation they receive in exchange for limited and transparent use of their personal data on which they have granted permission - as validated in [4].

Model developers participate on a PPIM by coproducing models with the data contributing individuals. These models extract insights of value from the raw personal data. A model may be as simple as extracting an individual's age from his or her Facebook data or as advanced as predicting an individual's preferred holiday destination using clustering techniques. PDPs are customised by selecting the output from one or more models together with an associated permitted usage and then instantaneously built-to-order at the completion of the customization process. The value proposition to model developers is the access right to the permitted personal data repository and the financial compensation they receive whenever a personal data product which comprises the results of one or more of their models is executed.

Data feed developers participate on a PPIM by developing feeds from new devices or services that generate or capture personal data into the centralised personalised data repository. The value proposition to data feed developers is the financial compensation they receive whenever a personal data product which comprises the raw data collected via one or more of their feeds is executed.

PDP consumers benefit participate on a PPIM by specifying the PDPs they require and purchasing access to them.

\subsection{Service concept design}

Here we outline the design of the service logic of a PPIM to fulfil the business logic and customer value propositions outlined above - from the perspective of four actor types: data contributing individuals, data feed and model developers and PDP consumers.

Data contributing individuals receive access to a centralized personal data store which captures (via a data feed /device interface) and securely stores their data. They receive requests for access to their personal data which, if accepted, result in financial compensation. Individuals receive access to a personal information dashboard which enables them to manage and control access to their personal data.

Data feed and model developers benefit from participating on a PPIM by gaining access to a market to promote and sell the fruit of their labours. The data feeds and models they develop are made available on the PPIM and are available to be incorporated into PDPs at build time on demand. When a PDP comprising a developer's data feed or model is executed the developer receives financial compensation. Developers also receive the ability to transparently track the use to which their components are being put and the financial compensation they are receiving.

PDP consumers benefit by participating on a PPIM by gaining the ability to co-design, co-build, then purchase and execute PDPs with the PPIM. It is well known that personal data is of great value to a wide range of businesses [50]. PDP consumers receive the ability to browse personal data assets such as templates and information which has been inferred and extracted from the raw materials of personal data by model developers. Via the consumer facing PDP dashboard, they receive a means to transparently co-create, preview, purchase, execute, delete, renew and monitor the PDPs. In line with best practice in a sharing economy [51], PDP consumers also receive the ability to validate the quality of the data to which they are buying access and the validity of the models they are incorporating into their products via a fair and transparent rating systems whereby the market can give feedback on the validity and utility of the models.

On a PPIM, PDPs can be co-created from four types of components: templates, data feeds, extracted information and permissions. The PDP consumer can utilise a template for a given type of PDP (targeted marketing, personal response, customer identification, etc.). The template is then populated with the data feeds (made possible by the data feed developers) and the information extracted from the data feeds (by the model developers). Finally, permission to execute PDP, in terms of time duration, frequency of use and mode of contact is incorporated into the PDP.

This service concept design fulfils individuals' expectations of transparency [36] (via the individuals' dashboard), opt out ability (by the ability to withhold and withdraw permission), fair 
compensation (via the payments system), low transaction costs and security of data. It also fulfils model developers' and data feed developers' expectations that PDP consumers can search for, locate and compare their offerings, and that they receive fair compensation for the use of them.

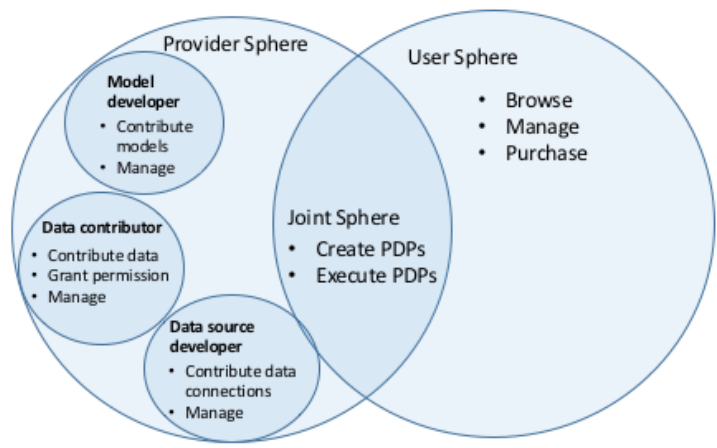

Figure 2: Provider, user and joint spheres of value creation on a PPIM

Figure 2 shows how, at the point in time the PDP is executed, its value-in-use [52] (value cocreation) is experienced by the PDP consumer in the joint sphere at the intersection of the user and providers spheres [53]. The PDP has been cocreated by the data contributors granting permission and the PDP consumer assembling, purchasing and executing the PDP (using a template co-produced by the model developer).

\subsection{Service architecture design}

The purpose of service architecture is to systematize and capture the aspects of the service enabled by a PPIM as an Industry platform. It does so by identifying the components, interfaces, degree of coupling, and commonality of sharing between components in the PPIM industry platform.

In the PPIM service architecture, there is a close relationship between the four stakeholders: data feed developers, model developers, data contributing individuals and PDP consumers in various PPIM value co-creation processes Data feed developers co-create value by facilitating the ingestion of new data feeds (in turn from the individuals' raw personal data). Model developers co-create value by inferring, predicting and extracting additional knowledge from the raw data. Data contributing individuals co-create value by granting permission for their personal data to be used, and PDP consumer co-creates value by constructing the PDP, paying for the right to use it and co-creating value-in-use by executing the PDP and integrating the inherent valuable PDP knowledge into their own valuecreating business activities.

The PDP templates and the data feed and model outputs are designed as modular components which enable reuse and adaptability to co-create customised PDPs. The four interfaces (APIs) share many common standardized elements as they interface to a common PDS. The dashboards share common elements such as PDPs, usage, payments and status of PDPs. The underlying PDS can be adapted to support PDPs for various uses including purely personal use, creation of PDPs and comparison between individuals.

The commonality between the API interfaces will be designed for extensibility to incorporate additional stakeholders, thereby facilitating the expansion of the 4-sided market instantiated in the platform prototype to an m-sided market $(m>4)$ as described in section 4.1. above.

\subsection{Service system design}

Here we outline the service system design which defines how the service value co-creation will be performed. The PPIM service system design is shown in Figure 3. A centralized cloud based Personal Data Store (PDS) comprising a distributed file system and a massively parallel processing database stores the individuals' personal data. Apps which can be installed on physical devices capture at source individuals' personal data. A data model in the PDS tracks which data feeds, models and individuals' raw data have been used by the consumers to co-create various PDPs.

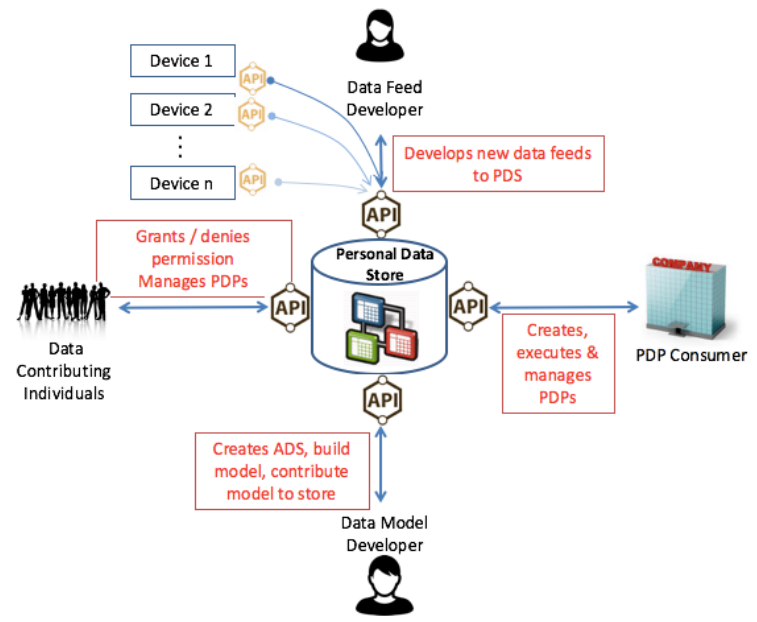

Figure 3: The PPIM service system design

The data captured at source on individuals' devices are transferred to the PDS. Consumers (buyers) co-create PDPs using raw data captured via data feeds and the outputs from models which extract and infer additional information from the raw data. The data model is utilized to track which data feeds, models and individuals contributed to the PDP. When the PDP is executed the contributors' accounts are credited appropriately (automatically).

The system requires database and file system administrators to maintain the PDS platform. It requires database file system data modellers (as opposed to personal data modellers) to maintain and 
extend the data model to incorporate new data stream. There is also a need for back-end admin staff to resolve disputes over billing and associated issues.

\subsection{Customer experience design}

Figure 4 shows the service experience blueprint for participation on a PPIM and its attendant service process flow for each customer type on the PPIM industry platform. PPIM platform customer experience is designed and described below in accordance with the cognitive, emotive and behavioural lenses of customer engagement [54:473].

Data contributing individuals interact with the PPIM by installing the custom built apps to collect their personal data on their behalf and to ingest and store them in the PDS.

Data contributing individuals' cognitive requirements are supported via a customer facing dashboard showing in real time which companies have purchased access to their personal data, the uses to which their personal data are being put, the PDPs in which their personal data are included and the revenue they have accrued through the use of their personal data. Data contributing individuals also receive requests to access their personal data via their chosen channel (email, SMS, IM etc.). The data contributing individuals' emotive experience of this service is designed to be one of trust engendered by the transparency and immediacy of the service which grants them visibility of and control over the uses to which their personal data are being put [36]. Their emotive needs of fairness and equity are addressed as they are compensated for the use of the valuable personal data they have generated.

Data feed developers and model developers are supported with modeller facing dashboards which allows them to monitor the utilization of their models and data feed in PDPs and to monitor the revenue generated by the use of those PDPs. Their behavioural interaction with the system entails them searching and browsing existing models and data feeds to avoid replication and the contribution of new models and data feeds to the PDS. The modellers' cognitive requirements for visibility and control of the uses to which their models and data feeds are being put are catered for via the modeller dashboards. Their emotive requirements for fairness and equity are fulfilled as they are compensated for the use of models and data feeds they have programmed and a means to expose their products to a wider audience.

Data feed developers' behavioural interaction with the PDS involves developing and contributing ingestion mechanisms for new devices or applications into the PDS via the PDS API. They match data fields between the device API and the PDS API and contribute to the PDS data model to model how the new data feed will be ingested and stored in the PDS and how it will relate to the other personal data in the PDS. Once the new data feed has been established the developer's ID is associated with that data feed and whenever a PDP comprising data from the developer's data feed is executed credit is associated with the developer's account. Using the developer facing dashboard the developer can view, manage and track funds in his or her account.

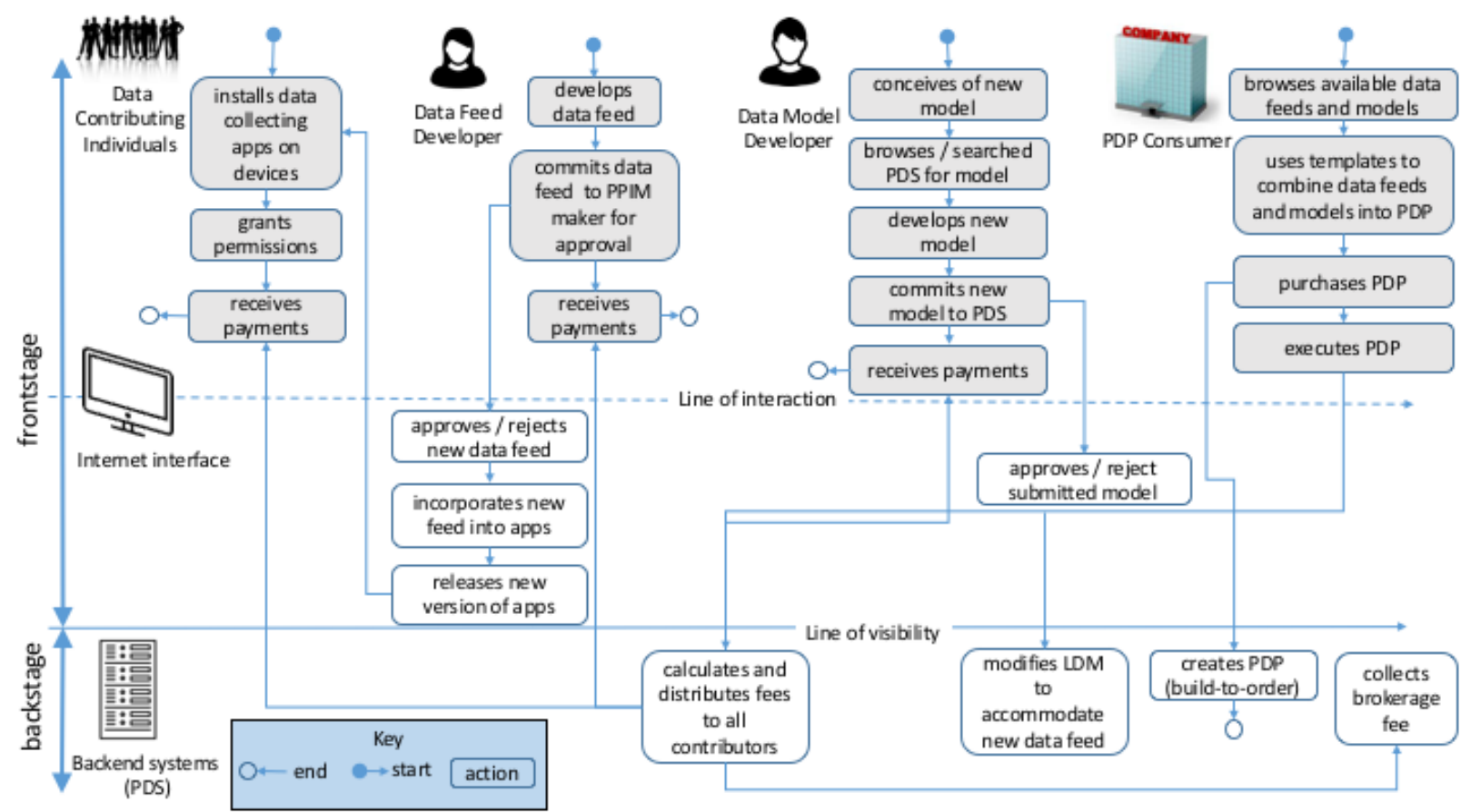

Figure 4: Service experience blueprint for participation on a PPIM 
Model developers' behavioural interaction with the system involves developing and contributing models which extract or infer information from the raw personal data stored in the PDS. Once the new model has been contributed to the PDS the developer's ID is associated with that model and whenever a PDP comprising information extracted or inferred using the developer's model is executed, credit is associated with the developer's account. Using the developer facing dashboard the developer can view, manage and track funds in his or her account.

PDP consumers' cognitive requirements are catered for via a consumer facing dashboard which connects to the PDS via an API. The PDP consumer uses the dashboard to browse, co-create, preview, execute and renew PDPs - thereby gaining knowledge of the products he or she has purchased and used. The emotive requirement for trust in the quality of the PDP is enhanced through the rating and customer feedback mechanisms.

Figure 5 shows a screen shot of the consumer facing dashboard. PDP consumers experience this service as the means by which they can interact (cocreate) with the personal information of individuals in a novel, legal, transparent and fair way.

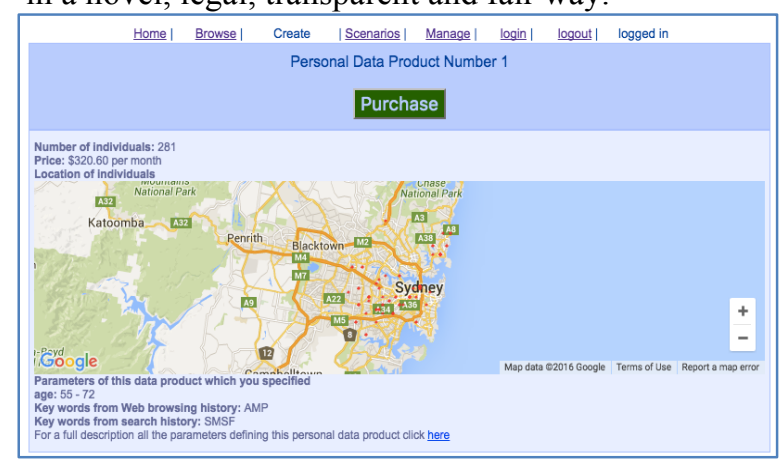

Figure 5: Screen shot of prototype PDP consumer facing dashboard

\subsection{Monetisation design}

The PPIM is monetized on a percentage payper-use model [55] (see Figure 4 above). Whenever a PDP is executed funds are transferred from the PDP consumer's account to the PDP contributors accounts (model developer, data feed developer and data contributing individuals). A brokerage fee is calculated as a percent of the transaction and transferred to the PPIM maker's account.

\section{Prototype}

Drawing on previous research [5], which examines the kinds of personal information individuals would be willing to share on a PPIM, we simulated a database of individuals and their associated permission granting activity. Using 3,603 permissions granted by 203 participants in a previous study [5] we simulated 43,200 permissions using stratified sampling.

We then developed a web interface in line with the above iSIM design to present the PPIM as a service system. This interface facilitated the provisioning of two popular end uses to which companies are likely to put personal data: personalised customer service [50,56], and targeted marketing [57]. This facility was combined with tools which allowed the PDP consumer to preview, purchase, execute and manage these PDPs to complete the prototype (see Figure 5 below).

\section{Evaluation}

Table 1: Indicative supportive quotations from interviewees

\begin{tabular}{|l|l|l|}
\hline Industry class & size & Indicative quotation \\
\hline $\begin{array}{l}\text { Finance and } \\
\text { Insurance (1) }\end{array}$ & small & $\begin{array}{l}\text { "If it works and works well } \\
\text { it would an incredibly } \\
\text { powerful tool." }\end{array}$ \\
\hline $\begin{array}{l}\text { Personal and } \\
\text { Other Services } \\
\text { (1) }\end{array}$ & large & $\begin{array}{l}\text { "No question about it. } \\
\text { Incredibly valuable." }\end{array}$ \\
\hline $\begin{array}{l}\text { Accommodation, } \\
\text { Cafes and } \\
\text { Restaurants }\end{array}$ & micro & $\begin{array}{l}\text { "It could, there would be a } \\
\text { huge number of uses [to } \\
\text { which it could be put]." }\end{array}$ \\
\hline $\begin{array}{l}\text { Personal and } \\
\text { Other Services } \\
\text { (2) }\end{array}$ & med & $\begin{array}{l}\text { "Yes, this system would } \\
\text { have benefits for } \\
\text { companies, - it would } \\
\text { reduce cost of acquisition." }\end{array}$ \\
\hline $\begin{array}{l}\text { Government } \\
\text { Administration } \\
\text { and Defence }\end{array}$ & med & $\begin{array}{l}\text { "I really like it .. [it's a } \\
\text { very] interesting concept, I } \\
\text { like the prototype." }\end{array}$ \\
\hline $\begin{array}{l}\text { Finance and } \\
\text { Insurance (2) }\end{array}$ & large & $\begin{array}{l}\text { "It's almost limitless the } \\
\text { things you could do ... } \\
\text { [with such a platform]." }\end{array}$ \\
\hline $\begin{array}{l}\text { Communication } \\
\text { Services }\end{array}$ & small & $\begin{array}{l}\text { "It would be gold for B2C } \\
\text { companies." }\end{array}$ \\
\hline Education & $\begin{array}{l}\text { "We would certainly use } \\
\text { this to reach new clients." }\end{array}$ \\
\hline
\end{tabular}

Following Yin [41], we identify, compare and contrast the main themes in the interviewees' responses. Of the eight experts interviewed, all expressed broadly the opinion that the PPIM would have utility for the business in which they worked. Table 1 contains indicative supportive quotations from each of the interviewees. One interviewee offered to be part of a pilot program to test the proposed PPIM in practice.

One notable aspect of the interviews was the ability for interviewees to identify and propose novel ideas for PDPs which would be of relevance to their industries. Novel data products proposed include: an auto-form filling PDP which would reduce friction between company and customer, personalised risk estimation for insurance, personalised policy offers based on expiry of current policies and a recruitment PDP to allow companies to go direct to potential new hires, by-passing 
recruitment firms possibly implemented via a candidate search tool, a customer identification and authentication PDP, driver classification PDP based on driving behaviour data and PDPs which allow companies to infer customer intention based on geolocation data.

In addition to in-principle agreement that the proposed PPIM would be of utility, interviewees also proposed numerous additional features which would improve its viability. Such suggestions include the ability to define a segment of interest and be alerted when a pre-set number of individuals join the PPIM in that segment. Another suggestion made by multiple interviewees was the need for a mechanism whereby the return on investment could be measured by the company using the PPIM.

\section{Conclusion}

Using the iSIM [11] and consistent with the Design Science methodology [7-9] this paper designs a PPIM as an Industry Platform. The proposed design is instantiated as a prototype which was evaluated using qualitative interview methods [22].

This paper reveals that the proposed industry platform model for the PPIM incorporating open access to model developers and data feed developers resolves the scalability concerns raised in prior research by obviating the need for a single organisation to have to develop all data ingestion and data modelling aspects of the PPIM in house.

All the interviewed experts broadly agreed that the proposed PPIM as an industry platform represents a service which would have multiple applications to a multiplicity of business types. They also demonstrated an ability to devise and envision novel data products (of value to the consumers' businesses) which would be facilitated by such a market.

This finding is significant as it lends weight to the argument that the industry platform conceptualisation of a PPIM has broad appeal to business of varying sizes and industry types. It also confirms the efficacy of iSIM as an effective method to design and commercialise a novel industry platform service.

However, this study also shows that more research is needed to develop additional features of the PPIM to ensure it is palatable to both individuals and businesses. Evaluation showed that the development of a method to track and measure return on investment is particularly pressing.

\section{Further research}

Basing the prototype for a PPIM on simulated data is a clear limitation for this paper. To better understand company's appetite to participate on a
PPIM there is a need to conduct a proof-of-concept project in the real world. An additional limitation is the limited sample size of the evaluation panel. A larger survey of potential PDP consumers would give a more informative insight into the viability of a PPIM.

Furthermore, this paper concerns itself with the design and evaluation of a workable PPIM and its utility from a business perspective. Further research is needed to refine the proposed design taking into account the feedback gathered in the semi-structured interviews, such as ability to track and measure return on investment.

There is also a need for further research into platform emergence and evolution in the context of a PPIM - i.e. what would be needed to germinate and develop a PPIM into an industry platform, in practice, from the ground up.

There is also considerable scope to research and develop in detail the API design to facilitate access to the centralised data store in a PPIM and the data collection mechanisms which initiate the personal data collection process.

\section{References}

[1] S. Radicati, Mobile Statistics Report, 2013-2017, S. Radicati, Editor. 2013, The Radicati Group Inc.

[2] C. Rees, "Who owns our data?". Computer Law \& Security Review, 2014. 30(1): p. 75-79.

[3] S. Conger, J.H. Pratt and K.D. Loch, "Personal information privacy and emerging technologies". Information Systems Journal, 2013. 23(5): p. 401-417.

[4] R. Farrelly and E. Chew, "Towards a Primary Personal Information Market". Twelfth International Conference on Technology, Knowledge, and Society, 2016.

[5] R. Farrelly and E. Chew, "Who's in to Win?: Participation Rate in a Primary Personal Information Market". forthcoming.

[6] R. Farrelly and E. Chew. "Designing a Personal Information Transaction Object". in System Sciences (HICSS), 2016 49th Hawaii International Conference on. 2016. Hawaii: IEEE.

[7] K. Peffers, T. Tuunanen, C.E. Gengler, M. Rossi, W. Hui, V. Virtanen and J. Bragge, "The design science research process: a model for producing and presenting information systems research". Proceedings of the first international conference on design science research in information systems and technology (DESRIST 2006), 2006: p. 83-106.

[8] K. Peffers, T. Tuunanen, M. Rothenberger and S. Chatterjee, "A Design Science Research Methodology for Information Systems Research". Journal of Management Information Systems, 2007-8. 24(3): p. 45-77. 
[9] A. Hevner, S. March, J. Park and S. Ram, "Design Science in Information Systems Research". MIS Quarterly, 2004. 28(1): p. 75-105.

[10] M.W. Krueger, E.K. Chew, Z.M. Ouetani and R. Gitzel. "Integrative Service Innovation: An Industrial Use Case". in Business Informatics (CBI), 2015 IEEE 17th Conference on. 2015. IEEE.

[11] E.K. Chew, "iSIM: An integrated design method for commercializing service innovation". Information Systems Frontiers, 2015: p. 1-22.

[12] B. Kitchenham, O.P. Brereton, D. Budgen, M. Turner, J. Bailey and S. Linkman, "Systematic literature reviews in software engineering-a systematic literature review". Information and Software Technology, 2009. 51(1): p. 7-15.

[13] S.C. Wheelwright and K.B. Clark, Creating project plans to focus product development. 1992: Harvard Business School Pub.

[14] A.P. Lehnerd, Revitalizing the manufacture and design of mature global products. 1987, National Academy Press, Washington, DC. p. 49-64.

[15] M. Muffatto and M. Roveda, "Product architecture and platforms: a conceptual framework". International Journal of Technology Management, 2002. 24(1): p. 1-16.

[16] M. Iansiti and R. Levien, The keystone advantage: what the new dynamics of business ecosystems mean for strategy, innovation, and sustainability. 2004: Harvard Business Press.

[17] A. Tiwana, B. Konsynski and A.A. Bush, "Research commentary-Platform evolution: Coevolution of platform architecture, governance, and environmental dynamics". Information Systems Research, 2010. 21(4): p. 675-687.

[18] L.D. Thomas, E. Autio and D.M. Gann, "Architectural leverage: putting platforms in context". The Academy of Management Perspectives, 2014. 28(2): p. 198-219.

[19] A. Gawer and M.A. Cusumano, "Industry platforms and ecosystem innovation". Journal of Product Innovation Management, 2014. 31(3): p. 417-433.

[20] L. Muzellec, S. Ronteau and M. Lambkin, "Twosided Internet platforms: A business model lifecycle perspective". Industrial Marketing Management, 2015. 45: p. 139-150.

[21] C.Y. Baldwin and C.J. Woodard, "The architecture of platforms: a unified view". Harvard Business School Finance Working Paper, 2008(09-034).

[22] G. Toppenberg, S. Henningsson and B. Eaton. "Reinventing the Platform Core Through Acquisition: A Case Study". in 2016 49th Hawaii International Conference on System Sciences (HICSS). 2016. IEEE.
[23] A. Gawer, "Bridging differing perspectives on technological platforms: Toward an integrative framework". Research Policy, 2014. 43(7): p. 1239-1249.

[24] A. Mashhadi, F. Kawsar and U.G. Acer, "Human Data Interaction in IoT: The ownership aspect". Internet of Things (WF-IoT), 2014 IEEE World Forum on, 2014: p. $159-162$.

[25] T. Hoeren, "Big data and the ownership in data: recent developments in Europe". European Intellectual Property Review, 2014. 36(12): p. 751-754

[26] M. Schunter, "Data Security and Privacy in 2025?". Secure Data Management, 2014: p. 37-41.

[27] K. Nissim, S. Vadhan and D. Xiao, "Redrawing the boundaries on purchasing data from privacy-sensitive individuals". Proceedings of the 5th conference on Innovations in theoretical computer science, 2014: p. 411422.

[28] I. Li, Y. Medynskiy, J. Froehlich and J. Larsen, "Personal informatics in practice: improving quality of life through data". CHI '12 Extended Abstracts on Human Factors in Computing Systems, 2012: p. 2799-2802.

[29] I. Li, A. Dey and J. Forlizzi, "A stage-based model of personal informatics systems". Proceedings of the SIGCHI Conference on Human Factors in Computing Systems, 2010: p. 557-566.

[30] A. Shimojo, S. Kamada, S. Matsumoto and M. Nakamura, "On integrating heterogeneous lifelog services". Proceedings of the 12th International Conference on Information Integration and Web-based Applications \& Services, 2010: p. 263-272.

[31] D. Kyriacou and H. Davis, "Moving Towards LifeLong User Modeling". Advanced Learning Technologies, 2008. ICALT '08. Eighth IEEE International Conference on, 2008: p. 647-648.

[32] M. Thapliyal, H.L. Mandoria and N. Garg, "Data Security Analysis in Cloud Environment: A Review". 2014.

[33] M. Sugumaran, B.B. Murugan and D. Kamalraj, "An Architecture for Data Security in Cloud Computing". Computing and Communication Technologies (WCCCT), 2014 World Congress on, 2014: p. 252-255.

[34] S. Milyaeva and D. Neyland, "On re-devising markets, re-locating value: Online personal data and 'empowering'privacy". Forthcoming.

[35] S. Wang, S. Zheng, L. Xu, D. Li and H. Meng, "A literature review of electronic marketplace research: Themes, theories and an integrative framework". Information Systems Frontiers, 2008. 10(5): p. 555-571.

[36] S. Spiekermann and A. Novotny, "A vision for global privacy bridges: technical and legal measures for international data markets". Computer Law \& Security Review, 2015.31(2): p. 181-200. 
[37] C. Aperjis and B. Huberman, "A Market for Unbiased Private Data: Paying Individuals According to their Privacy Attitudes". Available at SSRN 2046861 (2012). 2012.

[38] Y.A. de Montjoye, S.S. Wang, A. Pentland, D.T.T. Anh and A. Datta, "On the Trusted Use of Large-Scale Personal Data". IEEE Data Eng. Bull., 2012. 35(4): p. 58.

[39] Y.A. de Montjoye, E. Shmueli, S.S. Wang and A.S. Pentland, "openPDS: Protecting the Privacy of Metadata through SafeAnswers". PloS one, 2014. 9(7): p. e98790.

[40] S. Sevignani, "The commodification of privacy on the Internet". Science and Public Policy, 2013. 40(6): p. 733-739.

[41] R.K. Yin, Case study research: Design and methods. 2013: Sage publications.

[42] E. Gummesson, "Relationship marketing and a new economy: it's time for de-programming". Journal of Services Marketing, 2002. 16(7): p. 585-589.

[43] A. Karunakaran and S. Purao, Designing for recombination: process design through template combination, in Design Science Research in Information Systems. Advances in Theory and Practice. 2012, Springer. p. 36-51.

[44] A. Knol, H. Sol and J. Van Wamelen, Decision enhancement for sourcing with shared service centres in the Dutch government, in Design Science Research in Information Systems. Advances in Theory and Practice. 2012, Springer. p. 239-255.

[45] S. Nenonen and K. Storbacka, "Business model design: conceptualizing networked value co-creation". International Journal of Quality and Service Sciences, 2010. 2(1): p. 43-59.

[46] ABS. Australian and New Zealand Standard Industrial Classification. 1993 [accessed 2015 15th Sept]; Available from: http://www.abs.gov.au/AUSSTATS/abs@.nsf/66f306f50 3e529a5ca25697e0017661f /7cd8aebba7225c4eca25697e 0018faf3!OpenDocument.
[47] K.M. Eisenhardt, "Building theories from case study research". Academy of management review, 1989. 14(4): p. $532-550$.

[48] N. King, "Qualitative methods in organizational research: A practical guide". The Qualitative Research Interview, 1994.

[49] R.G. McGrath, "Business models: a discovery driven approach". Long range planning, 2010. 43(2): p. 247-261.

[50] I. World Economic Forum and Bain \& Company. "Personal data: The emergence of a new asset class". in An Initiative of the World Economic Forum. 2011.

[51] A.D. Thierer, C. Koopman, A. Hobson and C. Kuiper, "How the Internet, the Sharing Economy, and Reputational Feedback Mechanisms Solve the'Lemons Problem"'. Available at SSRN 2610255, 2015.

[52] S.L. Vargo and R.F. Lusch, "Evolving to a new dominant logic for marketing". Journal of marketing, 2004. 68(1): p. 1-17.

[53] C. Grönroos and P. Voima, "Critical service logic: making sense of value creation and co-creation". Journal of the Academy of Marketing Science, 2013. 41(2): p. $133-150$

[54] P. Frow, S. Nenonen, A. Payne and K. Storbacka, "Managing Co-creation Design: A Strategic Approach to Innovation". British Journal of Management, 2015. 26(3): p. $463-483$.

[55] M. de Reuver, T. Haaker, F. Nikayin and R. Kosman, Designing Viable Multi-sided Data Platforms: The Case of Context-Aware Mobile Travel Applications, in Open and Big Data Management and Innovation. 2015, Springer. p. 354-365.

[56] M. Gualtieri, Predictive Apps Are The Next Big Thing In Customer Engagement. 2013, Forrester.

[57] J. Rose, O. Rehse and B. Röber, "The value of our digital identity”. Boston Cons. Gr, 2012. 